\title{
O DESENVOLVIMENTO DA FORMA-VALOR E A EXPLICAÇÃO DO DINHEIRO EM $O$ CAPITAL DE KARL MARX ${ }^{I}$
}

\author{
Christian Iber $^{2}$
}

\begin{abstract}
Resumo: Na minha contribuição eu discuto, em quatro momentos, a explicação marxiana do dinheiro no contexto do desenvolvimento da forma-valor: primeiramente, expõe-se a importância e o significado do desenvolvimento da forma-valor para a explicação do dinheiro em $O$ Capital. Em um segundo momento são feitas considerações sistemáticas sobre a transição da análise da mercadoria para o desenvolvimento da forma-valor. Em terceiro lugar, apresenta-se, em forma de teses, o desenvolvimento da forma-valor na segunda edição de $O$ Capital e sua diferença em relação com a primeira edição e aprecia-se o seu proveito para a explicação do dinheiro. A contribuição defende a tese de que o dinheiro é a existência objetiva universalmente obrigatória do valor, do poder de disposição privado, excludente social sobre a riqueza social. A fonte do valor-dinheiro dos produtos é o trabalho como humano abstrato que se comporta indiferentemente frente a seu caráter como concreto-útil e, portanto, é taxado apenas conforme sua quantidade, e precisamente conforme seu dispêndio temporal respectivamente médio. Conclusivamente, esclarece-se resumidamente o significado da diferença no desenvolvimento das formas do valor e da explicação do dinheiro entre a primeira e segunda edição de $O$ Capital em forma de esquemas.
\end{abstract}

Palavras-chave: Valor de troca. Valor. Forma-valor. Dinheiro.

\begin{abstract}
In my contribution, I discuss Marx' explication of money in the context of the development of the form of value in four moments: The first instance emphasizes the significance and the importance of the development of the form of value for the explication of the money in the Capital. The second step systematically deals with the transition of the analysis of the commodity to the development of the form of value. Thirdly, we represent in form of thesis the development of the form of value of the second edition in their difference to the first edition of the Capital and recognize its advantage for the explication of money. The contribution defends the thesis that the money is the generally binding objective existence of the value, the private, exclusive social power of disposition over the social wealth. The source of the money-value of products is the abstract human labor behaving indifferently against its character as concrete useful labor and therefore only valued according to its respectively average temporal expenditure. Finally, I explain the significance of the difference in the development of the forms of value and the explication of money between the first and second edition of the Capital by means of schemes.
\end{abstract}

Keywords: Exchange value. Value. Form of value. Money.

\footnotetext{
${ }^{1}$ A presente contribuição é a versão revista do item sobre a forma-valor do meu livro: Christian Iber. Elementos da teoria marxiana do capitalismo. Um comentário sobre o livro I de O Capital de Karl Marx. Porto Alegre: Editora fi/EdiPUCRS, 2013, p. 84-111.

${ }_{2}^{2}$ Possui doutorado em Filosofia - Instituto de Filosofia da Livre Universidade de Berlim (1986). Atualmente é Professor Doutor do Instituto de Filosofia da Universidade Livre de Berlin, Alemanha. O diploma de doutorado é, ao mesmo tempo, diploma de formatura em três faculdades: Filosofia, Filologia Germânica e Politologia. Atualmente é pesquisador do Programa Nacional de Pós-Doutorado (PNPD) na Pontifícia Universidade Católica do Rio Grande do Sul (PUCRS / Brasil).
} 
A contribuição defende a tese de que o dinheiro é a existência objetiva universalmente obrigatória do valor, do poder de disposição privado, excludente social sobre a riqueza social. A fonte do valor-dinheiro dos produtos é o trabalho como humano abstrato que se comporta indiferentemente frente a seu caráter como concreto-útil e, portanto, é taxado apenas conforme sua quantidade, e precisamente conforme seu dispêndio temporal respectivamente médio. Conclusivamente, esclarece-se resumidamente o significado da diferença no desenvolvimento das formas do valor e da explicação do dinheiro entre a primeira e segunda edição de $O$ Capital em forma de esquemas.

\section{A importância e o significado do desenvolvimento da forma-valor em $O$ Capital}

O programa do desenvolvimento da forma-valor em $O$ Capital consiste em decifrar o "enigma do dinheiro" (CI, p. 173). A tese de Marx é que a relação simples do valor entre duas mercadorias já contém a estrutura da forma-dinheiro. O desenvolvimento da forma-valor pode ser apreendido como a reconstrução teórica da forma-dinheiro, visando responder à questão: ‘o que é o dinheiro?' O status dessa reconstrução é lógico-sistemático, quer dizer, ela não formula graus do desenvolvimento histórico do dinheiro. Não obstante, na segunda edição de O Capital, Marx desenvolve - aconselhado por Friedrich Engels (cf. carta a Marx, dia 16 de junho de 1867. In: MEW 31, 303s.) - reflexões sobre a correspondência entre os níveis lógico-sistemático e histórico. No contexto da análise da forma-valor, junto com a apresentação da necessidade da forma-dinheiro, resulta a tese do fetichismo da mercadoria e do dinheiro. A análise da forma-valor contém, portanto, os principais elementos da teoria do dinheiro e a crítica do dinheiro de Marx.

Diferentemente da Contribuição à crítica da economia política, de 1859, Marx tenta decifrar, em $O$ Capital, o enigma do dinheiro sem a apresentação do processo de troca, mas através da sequência das formas do valor. A Contribuição à crítica ainda não contém a separação entre a análise da forma-valor e o processo de troca. Aí o desenvolvimento da mercadoria e do dinheiro ocorre juntamente com o desenvolvimento do processo de troca. Em O Capital, o nível do processo de troca está claramente separado do nível da análise da formavalor. Nesta última obra, o centro de gravidade da explicação do dinheiro reside na análise da forma-valor, a qual antecede o processo de troca. Sem dúvida, na análise do processo de troca, O Capital retorna ao desenvolvimento do dinheiro, mas agora num outro contexto. Na análise da forma-valor, trata-se da dedução do dinheiro a partir das determinações econômicas da forma-mercadoria. Por sua vez, na análise do processo de troca, trata-se da apresentação de

\begin{tabular}{|l|l|l|l|l|}
\hline Q Povista Dialectus & Ano 3 & n. 8 & Janeiro - Agosto 2016 & p. 1-15 \\
\hline
\end{tabular}


como a realidade do dinheiro se faz valer enquanto necessidade no ato de troca dos possuidores de mercadorias.

O nível da forma-valor, no qual, em $O$ Capital, a dedução do dinheiro ocorre primeiramente, é somente uma estrutura parcial do processo de troca, não este mesmo. A análise da forma-valor abstrai do movimento do processo de troca, isto é, dos possuidores de mercadorias, os quais, no seu agir, realizam as relações das mercadorias. A análise da formavalor ocorre, portanto, na abstração da estrutura global pressuposta do processo de troca e, com isso, também da perspectiva dos participantes que operam a troca.

Enquanto na Contribuição à crítica deduz-se o dinheiro somente como resultado do desenvolvimento do processo de troca, $O$ Capital tem um programa duplo: o desenvolvimento deve, primeiramente, mostrar que o dinheiro pode ser explicado apenas a partir da estrutura da mercadoria, e, em segundo lugar, que o processo de troca, enquanto relação social dos sujeitos que mediatizam as determinações das mercadorias, pode somente ser realizado por meio do dinheiro. A primeira edição de $O$ Capital ocupa uma posição intermediária. Aí o desenvolvimento das formas do valor chega somente até o equivalente universal. O passo para o dinheiro ainda não foi dado. Também aí o dinheiro é considerado somente no âmbito da apresentação do processo de troca.

2. Anotações sobre a transição da análise da mercadoria para a análise da forma-valor

O primeiro capítulo já realiza o movimento que o livro inteiro de $O$ Capital descreve, na medida em que, partindo do valor de troca, que aparece na relação de troca de duas espécies de valores de uso, vai-se ao fundamento do valor de troca, como o valor se mostra, e, então, com a forma-valor, retorna-se ao valor de troca como sendo a forma de manifestação necessária do valor. Com isso, a determinação inicial do valor de troca experimenta uma correção. Lembremo-nos do seguinte: a mercadoria está determinada por dois fatores, quais sejam, o valor de uso e o valor de troca. Enquanto que, por um lado, os valores de uso e as necessidades relacionadas com eles são incomensuráveis entre si, por outro, o valor de troca, a saber, a relação de troca quantitativa, que consiste na substituição de um quantum de bens aproveitáveis por uma quantidade determinada de outros, baseia-se na equiparação praticada entre as coisas mais diversas. Essa equiparação, por sua vez, pressupõe um terceiro fator comum, a saber, o valor, que não resulta nem do valor de uso, ou seja, do ponto de vista da necessidade dos participantes, nem é uma abstração arbitrária. Antes, ele é o que é medido na

\begin{tabular}{|l|l|l|l|l|}
\hline Qovista Qialectus & Ano 3 & n. 8 & Janeiro - Agosto 2016 & p. 1-15 \\
\hline
\end{tabular}


relação quantitativa da troca de bens, sua qualidade idêntica. O valor é, portanto, a medida imanente às mercadorias nas suas relações de troca.

Como o conceito de valor é concebido em Marx? O valor é, como um quantum do trabalho humano abstrato objetivado, um quantum do poder de disposição social privado, excludente sobre os bens para a troca que existe como sendo propriedade objetiva dos produtos - algo literalmente louco. ${ }^{3}$ A substância e a fonte do valor é o trabalho como trabalho humano abstrato, quer dizer, como abstração efetuada do seu conteúdo especial e da sua finalidade, a qual o constitui como trabalho útil. O trabalho abstrato, portanto, é taxado somente segundo a sua quantidade. Nesse caso, as horas de trabalho realmente empregadas não são decisivas, mas - já que se trata, de fato, de um quantum do poder de disposição social sobre os bens para a troca - o quantum de trabalho mediamente necessário sob as condições normais da produção e para as necessidades sociais dominantes. Na medida em que o trabalho conta exclusivamente pelo fato de que ele gera o valor-mercadoria, portanto, ele somente chega a ser aplicado onde vale a pena para a produção de mercadorias, ele é de fato reduzido ao "dispêndio de força humana de trabalho em sentido fisiológico" (CI, 172). ${ }^{4}$

Marx concebe a transição para a forma-valor como o desenvolvimento da contradição da mercadoria. ${ }^{5}$ A contradição da mercadoria consiste no fato de que ela tem de ser, por um lado, o valor de uso para qualquer necessidade e, por outro, o valor de uso é meramente o material indiferente do valor, nesse caso "na objetividade de seu valor não está contido um único átomo de matéria natural" (CI, 173). No valor da mercadoria, o seu valor de uso está ao mesmo tempo negado, de modo que sem a realização do valor não é possível ter acesso ao

\footnotetext{
${ }^{3}$ Já no ano de 1842 Marx vê no valor o núcleo econômico da propriedade privada, assim como a propriedade privada é nada mais do que a forma do direito do valor: "O valor é o ser aí burguês da propriedade" ("Sessões da $6^{\mathrm{a}}$ assembleia do Estado renano. De um renano. Terceiro artigo: debates sobre a lei do furto de madeira [1842]. In: MEW 1, 109-146, aqui: 114).

${ }^{4} \mathrm{O}$ diagnóstico da redução naturalista do trabalho pertence à avaliação negativa de Marx da determinação social do trabalho como abstrato e não apresenta de modo nenhum uma "posição naturalista do trabalho abstrato" (Heinrich 1999, 214). Porque a determinidade espiritual da finalidade do trabalho existe por inteiro nas condições postas pela propriedade privada, portanto, é determinada separadamente do trabalhador, sua atividade é reduzida ao mero dispêndio de suas forças físicas naturais. Nisso fica cabalmente manifestado que o trabalho formador de valor é o trabalho submetido à propriedade e, com isso, à serviço da propriedade que se aumenta com ele.

${ }^{5} \mathrm{O}$ déficit da maior parte das interpretações da dialética consiste em conectar a explicação teórica de uma contradição na coisa, de uma contradição objetiva ou 'dialética' com o abandono do princípio lógicoargumentativo da contradição (cf. Becker 1972, 61s. e Göhler 1980, 37-43). A explicação de uma contradição objetiva é algo diferente do que se exprimir em declarações contraditórias sobre o objeto. O reconhecimento da proposição lógico-argumentativa da contradição inclui a intelecção na falsidade da proposição ontológica da contradição, segundo a qual não poderia haver contradições, pois a proposição lógico-argumentativa da contradição apenas pode ser provada através da comprovação de uma contradição na sua negação (cf. Hösle 1988, Bd. 1, 161-179; Iber 2015, 60).
}

\begin{tabular}{|l|l|l|l|l|}
\hline Q Rovista Qialectus & Ano 3 & n. 8 & Janeiro - Agosto 2016 & p. 1-15 \\
\hline
\end{tabular}


valor de uso da mercadoria. A circunstância, contudo, que no valor da mercadoria está dada de modo objetivo uma relação social, a força de comando privada sobre o trabalho socialmente necessário - o que Marx abalou ao falar do caráter fetichista da mercadoria torna necessário uma forma, na qual o valor, em contradição com o valor de uso do produto, chegue à apresentação como relação social das coisas: a forma-valor.

A mercadoria, analisada na análise da mercadoria nas suas determinações de valor de uso e valor, ainda não está pronta por meio da apresentação da sua contradição imediata. Está exigido o desenvolvimento da contradição como contradição. E isso ocorre na discussão da forma-valor. A explicação da mercadoria inclui, portanto, o desenvolvimento da forma-valor. A mercadoria está desenvolvida, primeiramente, na sua relação com o dinheiro, quer dizer, como mercadoria determinada por um preço. Com a concepção da forma-valor Marx critica, portanto, a separação da teoria do valor e do dinheiro na economia política clássica. ${ }^{6}$

3. Teses para o desenvolvimento da forma-valor na segunda edição de $O$ Capital e sua diferença em relação à primeira edição

1. O que deve ser explicado na análise da forma-valor simples (forma I) é a sua dupla fórmula: " $\mathrm{x}$ mercadorias $\mathrm{A}=\mathrm{y}$ mercadorias $\mathrm{B}$, ou $\mathrm{x}$ mercadorias $\mathrm{A}$ têm o valor de $\mathrm{y}$ mercadorias B" (CI, p. 174). A forma-valor simples tem a seguinte estrutura: a mercadoria A exprime o seu valor distinto do seu valor de uso, como valor de troca no valor de uso da mercadoria B.

Para Marx, a "verdadeira dificuldade" (CI, p. 174) reside na função diversa que ambas as mercadorias possuem, pois essa complica a compreensão da forma-valor. A mercadoria A desempenha o papel ativo, é seu valor que aparece no valor de uso da mercadoria B. A mercadoria B desempenha o papel passivo, pois serve como valor de uso para a expressão do valor. Marx denomina a posição da mercadoria A como "a forma de valor relativa", a posição da mercadoria B como "forma de equivalente" (CI, p. 174). ${ }^{7}$

$\mathrm{Na}$ forma-valor, a contradição imediata da mercadoria existe como oposição polar de duas mercadorias na forma-valor relativa e na forma equivalente, cujos lados contêm, respectivamente, em si mesmos, a contradição da mercadoria. Visto que, na expressão simples

\footnotetext{
${ }^{6}$ Backhaus acentua justificadamente que a teoria marxiana do valor é, ao mesmo tempo, teoria do dinheiro e se distingue, com isso, da teoria pré-monetária clássica do valor, mas também da teoria marxista do valor, que está caracterizada igualmente pelo 'esquecimento do dinheiro' (cf. Backhaus 1997, 94).

${ }^{7} \mathrm{O}$ fato de que na análise da forma do valor Marx conceitualiza o valor de uso da mercadoria $\mathrm{B}$ como "forma natural", tem sua justificação válida no fato de que na forma equivalente a base material das qualidades do valor de uso de uma coisa se torna forma de manifestação do valor e, com isso, é transformada em uma determinação econômica da forma, com o qual seu caráter do valor de uso é usurpado (cf. Krahl 1971, 39, 65, 74).
}

\begin{tabular}{|c|c|c|c|}
\hline Revista Dialectus & Ano 3 & n. 8 & Janeiro - Agosto 2016 \\
\hline
\end{tabular}


do valor, as mercadorias A e B estão distribuídas na forma-valor relativa e na forma equivalente como pontos de referências opostos, elas não podem entrar em cena, ao mesmo tempo, em ambas as formas na mesma expressão do valor. A dupla fórmula dá a entender que a forma-valor, com base na equiparação de duas mercadorias, que repousa sobre seu ser valor como objetivação do trabalho humano abstrato, é atualmente apenas a expressão do valor de uma mercadoria. ${ }^{8}$

A forma-valor simples representa, portanto, uma expressão do valor unilateralmente alinhada, sem a execução da relação inversa. Ela não é nenhuma relação de equivalente em sentido lógico-formal. Ela não é nem reflexiva, nem simétrica nem transitiva. Sem dúvida, a dupla fórmula inclui as "relações inversas" (CI, p. 175), mas não imediatamente ou diretamente, de modo que a equação tem de ser invertida. Primeiramente, a forma-valor na combinação com sua inversão resulta na estrutura de oposição cruzada em forma de chiasmo, recíproca, que marca a situação inicial do processo de troca. A forma-valor simples, que enquanto relação unilateralmente alinhada não está estruturada em forma de chiasmo, é meramente uma estrutura parcial do processo de troca. ${ }^{9}$ A análise da forma-valor não deve ser compreendida, portanto, como descrição teórica dirigida à atividade do ato de troca, ela é, antes, uma "análise dialética da forma" (Arndt 2012, 178) da expressão do valor, contida na relação de valor de duas mercadorias, de uma mercadoria por meio de uma outra.

2. Na sua relação com a outra mercadoria $\mathrm{B}$, a mercadoria $\mathrm{A}$ se constitui como mercadoria, na medida em que ela se relaciona a si mesma como valor e, ao mesmo tempo, se distingue de si mesma como valor de uso (cf. CI $1^{\text {a }}$ edição, MEGA² II.5, p. 29). Esse relacionar-se-a-si-mesma da mercadoria $\mathrm{A}$, na sua relação com a mercadoria $\mathrm{B}$, tange de modo peculiar também à mercadoria B. No interior da relação de valor ocorre um "quiproquó" (CI, p. 184) ou uma “inversão" (CI 1ª edição, suplemento, MEGA² II.5, p. 634) para a mercadoria-equivalente, que Marx resume nas três peculiaridades da forma equivalente. Sua análise efetua progressivamente o caminho da superfície à profundidade.

A inversão da forma natural ou física da mercadoria B em forma de manifestação do seu contrário, isto é, do valor da mercadoria A, é reconduzida à inversão do trabalho concreto

\footnotetext{
${ }^{8}$ Críticos da análise da forma-valor como Becker (1972, 48s.) e Lange (1978, 9s.) percebem uma contradição entre a equiparação do valor e a expressão do valor. Contudo, o exprimir da qualidade (valor) pressuposta em ambos os lados da equação na fórmula II não pode ser incomensurável com a própria equação que formula a fórmula I.

${ }^{9}$ Essa conexão entre a forma-valor e a estrutura do processo de troca Göhler destrinchou claramente na sua investigação teórica da estrutura comparativa do desenvolvimento dialético da mercadoria, do dinheiro e do processo de troca na Contribuição à crítica e em $O$ Capital (cf. Göhler 1980, 78s.).
}

\begin{tabular}{|l|l|l|l|l|}
\hline Qevista Dialectus & Ano 3 & n. 8 & Janeiro - Agosto 2016 & p. 1-15 \\
\hline
\end{tabular}


que produz a mercadoria B em forma de realização do seu oposto, a saber, o trabalho abstrato, que produz o valor da mercadoria $\mathrm{A}$, e essa inversão é reconduzida à auto contrariedade do trabalho privado produtor da mercadoria-equivalente, que é, ao mesmo tempo, trabalho em forma diretamente social. Na ordem sequencial das três peculiaridades da forma equivalente, constata-se a subordinação do trabalho social sob o poder da propriedade privada, com a qual o caráter do valor dos produtos do trabalho é posto, em geral, no mundo. Na mercadoriaequivalente, este caráter do valor dos produtos se envolve no modo de manifestação mistificante de uma obrigação objetiva. Parece como se a mercadoria-equivalente representasse, por natureza, um quantum do poder de disposição social sobre produtos e sobre o próprio trabalho.

3. Em todas as transições no desenvolvimento da forma-valor é comum que o respectivo grau mais elevado da expressão do valor critica o grau antecedente, quer dizer, remedia a sua deficiência. Nesse caso, a intelecção no conceito de valor como objetivação do trabalho abstrato-universal, do qual resulta a determinação da forma-valor, é também o pressuposto para a formulação da deficiência da primeira forma-valor. Essa consiste no fato de que a expressão casual do valor de uma mercadoria em uma espécie singular de mercadoria não corresponde à indiferença do valor frente ao valor de uso. A deficiência da forma de valor simples é superada na medida em que a mercadoria A entra em relação com várias mercadorias, portanto, pela ampliação e universalização da mercadoria-equivalente.

4. A forma II, a forma-valor total ou desdobrada, tem a seguinte estrutura: a mercadoria A exprime seu valor distinto do seu valor de uso como valor de troca não somente no valor de uso da mercadoria singular B, mas sim nos valores de uso de todas as mercadorias possíveis (B, C, D etc.). A forma-valor desdobrada se circunscreve principalmente à relação de troca da mercadoria A com todas as outras mercadorias. Como estrutura parcial do processo de troca, contudo, ela não diz nada sobre a estrutura efetiva da troca; ela se mantém na estrutura assimétrica da forma-valor simples.

5. A transição da forma II à forma III, a forma universal do valor, tem, em comparação com as outras transições do desenvolvimento da forma-valor, uma figura especial. Ele é obtida pela 'inversão' (cf. CI, p. 196) da forma-valor total ou desdobrada. Antes dessa transição, Marx se detém na apresentação pormenorizada das deficiências da forma desdobrada do valor. As deficiências da forma-valor desdobrada são, do lado da expressão relativa do valor, as seguintes: 1. a incompletude da expressão relativa do valor, 2. a multiplicidade das expressões diversas, desconexas do valor e 3. o valor relativo de cada

\begin{tabular}{|l|l|l|l|l|}
\hline Q Rovista Dialectus & Ano 3 & n. 8 & Janeiro - Agosto 2016 & p. 1-15 \\
\hline
\end{tabular}


mercadoria singular tem várias séries infindáveis de expressões do valor (cf. CI, p. 195). Essa terceira deficiência implica uma ampliação da forma-valor desdobrada do lado da forma-valor relativa, e desempenha o papel para a dedução da forma IV na primeira edição. A deficiência da forma-valor relativa se reflete, do lado da forma equivalente, nos seguintes pontos: 1 . a coexistência de inúmeras formas de equivalente apenas particulares, cada uma excluindo as demais e 2. o trabalho abstrato-universal se representa somente no circuito inteiro de suas formas particulares de manifestação do trabalho útil e, com isso, não de modo uniforme.

A deficiência da forma-valor desdobrada é, portanto, a não uniformidade da expressão do valor. Como elemento da série das formas de equivalente particulares, a mercadoriaequivalente particular representa, contudo, apenas sua função de expressão do valor; ele é substituível por qualquer outra mercadoria. Mas se o valor de uso de uma mercadoria tem somente a função de expressão do valor, a expressão do valor, todavia, não deve apresentar nenhuma restrição aos valores de usos particulares, pois isso contradiz à universalidade abstrata do valor, então, a função de expressão do valor - assim é o raciocínio de Marx - tem de competir a uma única mercadoria. Faz-se necessário a separação e a seleção de uma mercadoria dentro de todas as outras, que, como equivalente universal, se dissolve na função da expressão do valor. No conceito de mercadoria como equivalente universal excluído de todas as mercadorias, a deficiência da forma-valor desdobrada está remediada. Uma tal expressão do valor nada mais é do que a 'inversão' da forma II, a qual, como "relação inversa" (CI, p. 196), já está contida na forma desdobrada do valor.

Sem dúvida, na segunda edição de $O$ Capital, Marx menciona a ampliação da formavalor desdobrada do lado da forma-valor relativa, a qual foi indicada na terceira deficiência. Mas ele não a usa como elemento continuador, porque sua inversão não resulta no conceito de equivalente universal enquanto uma única mercadoria excluída de todas as outras mercadorias, não remediando, com isso, a deficiência da forma de valor desdobrada. Por isso é que ela permanece sendo desconsiderada pela transição.

6. Na sequência das formas do valor, com a forma III, a forma universal do valor, chega-se à forma perfeita do valor. Nessa forma, as mercadorias apresentam seu valor, primeiro, de maneira simples, porque em uma única mercadoria, e, segundo, de maneira unificada, porque na mesma mercadoria. Na forma de valor universal, a expressão do valor das mercadorias possui "uma forma socialmente válida" (CI, p. 198). Ao mesmo tempo, através do equivalente universal é estabelecida uma relação de valor universal entre as mercadorias. E, por fim, o trabalho privado que produz a mercadoria-equivalente conta como

\begin{tabular}{|c|c|c|c|c|}
\hline Rovista Dialectus & Ano 3 & n. 8 & Janeiro - Agosto 2016 & p. $1-15$ \\
\hline
\end{tabular}


“encarnação visível” (CI, p. 199) do caráter social do trabalho humano abstrato, o qual não só abstrai negativamente da peculiaridade dos trabalhos, mas reduz positivamente esses a mero dispêndio da forma de trabalho em sentido fisiológico.

7. A transição para a forma IV, para a forma-dinheiro, parte do raciocínio sistemático de que a mercadoria que atua como forma equivalente universal e que foi excluída de todas as outras ainda não se fixou definitivamente. Tão logo uma mercadoria determinada obtenha o monopólio da forma equivalente universal, ela se tornará mercadoria-dinheiro; a forma equivalente universal se transformará na forma-dinheiro; e a expressão simples relativa do valor se transformará na forma-preço.

Embora, para o desenvolvimento da forma-dinheiro, Marx recorra à forma II, ainda assim a argumentação histórica permanece decisiva para a forma IV, enquanto formadinheiro. Isto se deve ao fato de que a partir da forma II e da forma III não dá para se deduzir que, de todas as mercadorias, justamente o ouro se torne a única mercadoria-equivalente universal excluída, a qual atua, então, como dinheiro. O recurso à forma II tem apenas o sentido de mostrar que o ouro pode se confrontar com as mercadorias como dinheiro, porque antes da sua transformação em dinheiro ele já era mercadoria. Sem dúvida, é um fato histórico contingente que justamente o ouro se torne mercadoria-dinheiro, mas não que uma mercadoria determinada atue como mercadoria-dinheiro excluída. ${ }^{10}$

8. Qual significado tem, agora, a forte diferença entre a segunda edição de $O$ Capital no desenvolvimento da forma IV? Na primeira edição, Marx não introduz a forma-dinheiro com a forma IV como sendo a forma de valor final, mas o equivalente universal universalizado pela ampliação da forma III. Na primeira edição, para a universalização do equivalente universal na forma IV na saída da forma de valor universal (III), Marx recorre à forma ampliada da forma-valor desdobrada (II) do lado da forma-valor relativa (cf. CI $1^{\text {a }}$ edição, MEGA² II.5, p. 42s.). Na segunda edição, sem dúvida, Marx mencionou essas séries

10 A teoria marxiana do dinheiro, naturalmente, não acaba no capítulo 1 de $O$ Capital. Ela inclui o desenvolvimento das suas formas a partir da mercadoria como forma equivalente via a forma-dinheiro para a moeda, o papel-moeda do Estado e o dinheiro de crédito e, ulteriormente, para o dinheiro mundial na sua figura do ouro, ou seja, na sua versão moderna como concorrência dos dinheiros de crédito estatais nacionais. Mas é decisivo que, para Marx, o dinheiro também na sua forma idealizada, cunhada de forma estatal, não perde de modo nenhum sua determinação de ser a forma de manifestação do valor, portanto, corporificar o trabalho abstrato-universal. Na pesquisa de Marx, ao contrário, esforça-se atualmente por conduzir a prova que a introdução do dinheiro não precisa da mercadoria-dinheiro excluída. Essas esforços não percebem, em minha opinião, o fato de que o Estado, o qual se emancipa da matéria ouro do dinheiro, tem que garantir, com seu poder político, que o dinheiro de crédito emitido por ele pode ser usado como mercadoria-dinheiro real excluída ou dinheiro vivo. (cf. Decker, Hecker, Patrick 2016, 27-36).

\begin{tabular}{|c|c|c|c|c|}
\hline Rovista Dialectus & Ano 3 & n. 8 & Janeiro - Agosto 2016 & p. $1-15$ \\
\hline
\end{tabular}


diversas infinitas para cada mercadoria singular como sendo uma das deficiências da formavalor relativa desdobrada, mas não as usou para a continuação da forma-valor. Com a inversão dessas séries diversas infinitas das expressões relativas do valor para cada mercadoria, essas próprias mercadorias entram em cena como equivalentes universais. Contudo, em vista do caráter de exclusividade do equivalente universal, a ampliação e a inversão da forma II conduzem, conjuntamente, à contradição universal que suprassume a função social do equivalente universal pela auto exclusão (cf. CI, $1^{\text {a }}$ edição, cf. MEGA² II.5, p. 43).

No desenvolvimento do dinheiro a partir do processo de troca no capítulo 2 de $O$ Capital, Marx retoma também, na segunda edição, justamente essa contradição da forma IV da primeira edição (cf. CI, p. 220s.). Isso é um indício de que a ampliação e a inversão da forma II resultam na estrutura cruzada de oposição em forma quiasmo da situação inicial do processo de troca. Cada possuidor de mercadorias vê cada mercadoria alheia como equivalente particular da sua mercadoria e sua própria mercadoria, a qual deve ser alienada, contudo, como equivalente universal que deve poder ser trocada por todas as mercadorias, as quais lhe interessam somente como valores de uso especiais. No entanto, visto que cada possuidor de mercadorias defende o ponto de vista da sua mercadoria particular como equivalente universal contra todas as outras mercadorias, resulta que nenhuma mercadoria é o equivalente universal. Os agentes possuidores de mercadorias só podem superar essa situação complicada na medida em que eles efetuam a exclusão de uma mercadoria determinada como equivalente universal de todas as outras pela "ação social" (CI, p. 222), o que não significa outra coisa senão realizar o conteúdo da forma-dinheiro (IV) da segunda edição. "Eles não sabem disso, mas o fazem" (CI, p. 208). ${ }^{11}$

Na segunda edição, Marx evita a contradição universal do equivalente universal universalizado. Ele enfatiza o caráter de exclusividade do equivalente universal na forma III e

\footnotetext{
${ }^{11}$ O conceito de "ação social" tem uma nuance crítica. A diferença entre "agir" e "ação" reside no fato de que a última designa, com efeito, um agir voluntário, mas implementado sem raciocínio acerca da sua finalidade e de suas consequências (cf. Hegel. Filosofia do Direito § 117). Com efeito, Heinrich (1999, 227s.) vê que com o segundo capítulo de $O$ Capital acresce-se à análise da forma da mercadoria e do dinheiro a dimensão das atividades dos possuidores de mercadorias, todavia, ele as interpreta como atividades intencionais e conceitualiza, consequentemente, a formação do dinheiro como processo de acordo conscientemente intencionado, o que mal se distingue de uma fundamentação convencionalista. A formação do dinheiro como produto não diretamente intencionado das atividades dos possuidores de mercadorias se deixaria, antes, explicitar, no âmbito da teoria do jogo, que possui um conceito bem definido do agir estratégico dos sujeitos que perseguem sua vantagem (cf. por exemplo Dresher 1981).
}

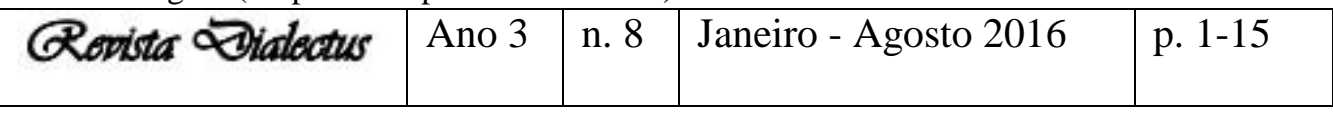


se detém na restrição do equivalente universal de uma mercadoria na forma IV. Esse passo é motivado objetivamente pelo fato de que a forma IV da primeira edição cai atrás da forma III, portanto, não supera de forma nenhuma as deficiências da forma II.

A estrutura do processo de troca não é apresentado no contexto do desenvolvimento das formas do valor. Seu desenvolvimento é objeto de uma investigação teórica dirigida à atividade no segundo capítulo de $O$ Capital. A explicação do dinheiro de Marx mostra-se, junto com a independentização do item sobre o caráter fetichista da mercadoria na segunda edição de $O$ Capital, como unidade diferenciada em si da teoria crítica da forma, do agir e da consciência.

9. O que é, portanto, segundo Marx, decifrar o enigma do dinheiro? O resultado do desenvolvimento da forma-valor é que a qualidade de valor das mercadorias, a qual é a determinação da finalidade dominante do trabalho, existe na troca na sua equiparação com uma mercadoria-equivalente universalmente válida, a qual atua como a forma-valor independente excluída da diversidade das mercadorias: o dinheiro - o dinheiro, o qual, com sua transformação em capital, mostra-se como o próprio organizador, a origem, a finalidade e o ponto de chegada da produção social. Já no desenvolvimento da forma do valor, O Capital de Marx se mostra, ao mesmo tempo, como unidade da apresentação e da crítica das categorias econômicas das relações sociais de poder e de dominação objetivamente obscurecidas. Pois o dinheiro é, para Marx, conforme seu conceito, a existência objetiva obrigatoriamente universal do valor, do poder de disposição privado social sobre a riqueza social e suas fontes. O dinheiro é o poder de acesso privado objetivamente obscurecido e, ao mesmo tempo, a exclusão organizada mediada objetivamente da riqueza social.

4. Esquemas

1. O desenvolvimento das formas do valor na segunda edição de $O$ Capital:

A forma valor simples, individual ou ocasional Marx explica com auxílio da fórmula dupla:

$\mathrm{x}$ mercadorias $\mathrm{A}=\mathrm{y}$ mercadorias $\mathrm{B}$ ou $\mathrm{x}$ mercadorias A têm o valor de y mercadorias B (CI, 174).

A mercadoria A é apresentada como "valor relativo" (CI, 174) com referência à mercadoria B e se encontra sob a "forma de valor relativa" (idem). A mercadoria B serve como equivalente

\begin{tabular}{|l|l|l|l|l|}
\hline Qevista Qialectus & Ano 3 & n. 8 & Janeiro - Agosto 2016 & p. 1-15 \\
\hline
\end{tabular}


para o valor da mercadoria A e se encontra sob a "forma de equivalente" (idem). Ambas as formas "se excluem [...] como polos opostos" (CI, 175).

$$
\begin{aligned}
& \text { a forma valor relativa } \\
& \text { mercadoria A }(1=\text { linho })
\end{aligned}
$$

I. VU/V (A) - VT (A) $\Rightarrow \quad$ VU/[V] (B) a forma equivalente mercadoria B [C, D...]

$(\mathrm{VU}=$ valor de uso, $\mathrm{VT}=$ valor de troca, $\mathrm{V}=$ valor $)$

$\mathrm{O}$ signo $\Rightarrow$ significa a equação da expressão do valor. A fórmula deve ser lida como: a mercadoria A exprime seu valor distintamente do seu valor de uso como valor de troca no valor de uso da mercadoria $B$. $\mathrm{O}$ valor da mercadoria $\mathrm{B}$ não chega à apresentação.

II. VU/V (A) - VT (A) $\quad \Rightarrow \quad$ VU/[V] (B, C, D ...)

II. VU/V (linho) - VT (linho) $\quad \Rightarrow \quad$ VU [V] (B, C, D...)

A forma III resulta pela "inversão" da forma II com o exemplo da mercadoria o linho na posição da forma valor relativa (II (inversão) = III):

III. VU/V (B, C, D...) - VT (B, C, D...) $\Rightarrow \quad$ VU/[V] (linho)

A forma IV, a forma-dinheiro, substitui o linho como equivalente universal pelo ouro:

IV. VU/V (A, B, C...) - VT (A, B, C...) $\Rightarrow \quad$ VU/[V] (ouro)

2. A diferença entre a primeira e a segunda edição de $O$ Capital no desenvolvimento da forma IV:

II. VU/V (A) - VT (A) $\Rightarrow$ VU/[V] $(B, C, D \ldots)$

Diversas séries infinitas das expressões relativas do valor para cada mercadoria: a ampliação da forma II do lado da forma valor relativa é formulada como a terceira deficiência na segunda edição:

\begin{tabular}{|c|c|c|c|c|}
\hline Rovista Dialectus & Ano 3 & n. 8 & Janeiro - Agosto 2016 & p. $1-15$ \\
\hline
\end{tabular}

$$
\begin{array}{lll}
\text { VU/V (B) - VT (B) } & \Rightarrow & \text { VU/[V] }(A, C, D \ldots) \\
\text { VU/V (C) - VT (C) } & \Rightarrow & \text { VU/[V] }(B, B, D \ldots)
\end{array}
$$




$$
\mathrm{VU} / \mathrm{V}(\mathrm{D})-\mathrm{VT}(\mathrm{D}) \quad \Rightarrow \quad \mathrm{VU} /[\mathrm{V}](\mathrm{A}, \mathrm{B}, \mathrm{C} \ldots)
$$

etc......

A forma IV da primeira edição resulta pela "inversão" da forma II ampliada do lado da forma valor relativa (II (inversão) $=$ IV):

$$
\begin{aligned}
& \text { IV VU/V ((A), B, C, D ...) - VT ((A), B, C, D ...) } \Rightarrow \quad \text { VU/[V] (A) } \\
& \text { ou: } \\
& \text { VU/V (A, (B), C, D...) - VT (A, (B), C, D...) } \Rightarrow \quad \text { VU/[V] (B) } \\
& \text { ou: } \\
& \text { VU/V (A, B, (C), D...) - VT (A, B, (C), D...) } \Rightarrow \quad \text { VU/[V] (C) }
\end{aligned}
$$

etc.........

A universalização do equivalente universal na forma IV da primeira edição conduz à contradição da auto-exclusão em razão do caráter de exclusão do equivalente universal.

3. A estrutura de oposição cruzada em forma de quiasmo como situação inicial do processo de troca (cf. CI, 220c.):

$$
\text { possuidor B possuidor A }
$$

$\begin{array}{cccc}\text { mercadoria A } & \text { VU } & & \neg \text { VU } \\ & \neg \text { VT } & & \text { VT }\end{array}$

$\begin{array}{ccc}\text { mercadoria B } \neg \text { VU } & & \text { VU } \\ & \text { VT } & \\ & & \neg \text { VT }\end{array}$

A mercadoria A é um não-valor de uso para seu possuidor (A), pois ele a quer alienar, e um valor de uso para seu não-possuidor (B), pois ele precisa dela e quer adquiri-la. Inversamente para a mercadoria B. A mercadoria A é o meio de troca (VT) para seu possuidor (A), já que ela serve para trocar a mercadoria B necessitada - mas não para seu não-possuidor (B), visto que para este ela é o valor de uso necessitado. Inversamente de novo para a mercadoria B.

\begin{tabular}{|l|l|l|l|l|}
\hline Q Povista Qialectus & Ano 3 & n. 8 & Janeiro - Agosto 2016 & p. 1-15 \\
\hline
\end{tabular}


A conexão entre a forma-valor e o processo de troca: a forma-valor em combinação com sua inversão resulta somente na estrutura da oposição cruzada em forma de quiasmo como situação inicial do processo de troca, a qual está caraterizada por um círculo e por uma contradição (cf. CI, 220s.). Essa situação os possuidores de mercadorias superam pela introdução da mercadoria-dinheiro excluída de todas as outras mercadorias como equivalente universal. A estrutura polar da oposição da forma-valor permanece conservada na relaçãomercadoria-dinheiro.

\section{Referências}

ARNDT, Andreas. Karl Marx. Versuch über den Zusammenhang seiner Theorie. Bochum: Germinal Verlag, 1985, 2. Aufl. Berlin: Akademie Verlag, 2012.

BACKHAUS, Hans-Georg. Dialektik der Wertform. Untersuchungen zur Marxschen Ökonomiekritik. Freiburg im Breisgau: ça ira-Verlag,1997.

BECKER, Werner. Kritik der Marxschen Wertlehre. Die methodische Irrationalität der ökonomischen Basistheorien des 'Kapital'. Hamburg: Hoffmann und Campe, 1972.

Decker, Peter/Hecker, Konrad, Patrick, Joseph. Das Finanzkapital. München: Gegenstandpunkt Verlag, 2016.

DRESHER, Melvin. The Mathematics of Games of Strategy: Theory and Applications. New York: Dover Publications, 1981.

GÖLER, Gerhard. Die Reduktion der Dialektik durch Marx. Strukturveränderungen der dialektischen Entwicklung in der Kritik der politischen Ökonomie. Stuttgart: Klett-Cotta, 1980.

HEGEL, Georg Wilhelm Friedrich. Grundlinien der Philosophie des Rechts. In: Werke in zwanzig Bänden Bd. 7. E. Moldenhauer, K. M. Michel (Orgs.). Frankfurt am Main: Suhrkamp, 1969s.

Filosofia do Direito. Tradução: Paulo Meneses, Agemir Bavaresco, Alfredo Moraes, Danilo Vaz, Curado R.M. Costa, Greice Ane Barbieri e Paulo Roberto Konzen. São Paulo: Editora Unisinos, 2010.

HEINRICH, Michael. Die Wissenschaft vom Wert. Die Marxsche Kritik der politischen Ökonomie zwischen wissenschaftlicher Revolution und klassischer Tradition. Überarbeitete und erweiterte Neuauflage. Münster: Westfälisches Dampfboot, 1999.

HÖSLE, Vittorio. 2. Bde. Hamburg: Felix Meiner. Verlag, 1988. Hegels System. Der Idealismus der Subjektivität und das Problem der Intersubjektivität.

IBER, Christian. Elementos da teoria marxiana do capitalismo. Um comentário sobre o livro I de O Capital de Karl Marx. Porto Alegre: Editora fi/EdiPUCRS, 2013.

\begin{tabular}{|l|l|l|l|l|}
\hline Q Rovista Dialectus & Ano 3 & n. 8 & Janeiro - Agosto 2016 & p. 1-15 \\
\hline
\end{tabular}


O desenvolvimento da essência como reflexão e a lógica das determinações de reflexão. Parte II. In: Ipseitas, São Carlos, vol. 1. n.2, p. 50-65, jul-dez, 2015 .

KRAHL, Hans-Jürgen. Zur Wesenslogik der Marxschen Warenanalyse. In: ders. Konstitution und Klassenkampf. Zur historischen Dialektik von bürgerlicher Emanzipation und proletarischer Revolution. Frankfurt am Main: Verlag Neue Kritik, 1971, 31-81.

LANGE, Ernst Michael. Wertformanalyse, Geldkritik und die Konstruktion des Fetischismus bei Marx. In: Neue Hefte für Philosophie 13. K. Cramer, R. Bubner, R. Wiehl (Orgs.). Heft 13. Göttingen: Vandenhoeck\&Ruprecht, 1978,1-46.

MARX-ENGELS Werke. Institut für Marxismus-Leninismus beim ZK der KPdSU und Institut für Marxismus-Leninismus beim ZK der SED (Org.); seit 1990: Internationale MarxEngels-Stiftung (Amsterdam) (Org.). Berlin (DDR): Dietz Verlag, 1975s. (cit.: MEW)

MARX-ENGELS. Gesamtausgabe. Institut für Marxismus-Leninismus beim ZK der KPdSU und Institut für Marxismus-Leninismus beim ZK der SED (Org.), Berlin/DDR - Moskau 1957-1989, ab 1992 Internationale Marx-Engels-Stiftung Amsterdam, Berlin - Amsterdam (Org.). (cit.: $\mathrm{MEGA}^{2}$ )

MARX, Karl. Das Kapital. Kritik der politischen Ökonomie, Bd. I (2. und 3. Aufl.). In: MEW 23.

O Capital, Livro I. Tradução Rubens Enderle. São Paulo: Boitempo, 2013.

Zur Kritik der politischen Ökonomie (1859). In: MEW 13.

Contribuição à crítica da economia política. $3^{\text {a }}$ edição. Trad. Maria Helena Barreiro Alves. São Paulo: Martins Fontes, 2003.

Das Kapital. Kritik der politischen Oekonomie. Erster Band. Buch I: Der Produktionsprozeß des Kapitals, Hamburg: Verlag von Otto Meissner 1. Aufl., 1867. (cit.: MEGA $^{2}$ II.5)

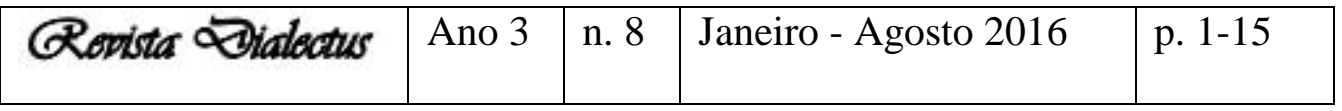

